\title{
Research on the Development of Medical Tourism Market under the Background of Population Aging
}

\author{
Qian Lin, Fuming Zhang \\ Shandong Xiehe University \\ 250100, Jinan, China
}

\begin{abstract}
With the rapid development of economy, the problem of population aging has become increasingly evident in China. However, population aging brings no serious damage to China's economic development, instead, produces the medical tourism market, an emerging market, with huge development potential. Given this situation, this paper studies and analyzes the development of medical tourism market in Jinan City, Shandong Province, hoping to provide references for the development of related industries.
\end{abstract}

Keywords-Medical tourism; Industry development; Economic growth; Population aging

\section{INTRODUCTION}

In the past two years, China's economic growth rate has begun to slow down, and outstanding issues in some areas have begun to appear. Under the impact of the Internet, the traditional offline economic model has undergone very serious challenges. However, under the background of the rise of the middle class, consumption has been constantly escalating. People are willing to go out for tourism and consumption. This is also a good thing for the development of the tourism industry. At the same time, as the aging society in our country intensifies, the medical industry will introduce new development opportunities.

In recent years, the number of medical tourism has risen rapidly, which has prompted a new consumption patterns. The World Health Organization predicts that by 2022, tourism will account for $11 \%$ of global GDP, and the large-scale health industry will account for $12 \%$. The organic combination of medical and tourism industries will become a new bright spot in the modern service industry and an important economy growth point. The World Medical Tourism Association predicts that the global medical tourism industry will maintain an annual growth rate of $15 \%$ to $25 \%$

Medical tourism has been around for thousands of years. In fact, archaeological evidence from the third millennium B.C. suggests that people in ancient Mesopotamia traveled to the temple of a healing god or goddess at Tell Brak, Syriato heal eye disorders. A couple millennia later the Greeks and Romans would travel by foot or boat to spas and cult centers all over the Mediterranean. The Asclepia Temples, dedicated in honor of the Greek god of medicine, were some of the world's first healing centers. Pilgrims would come and stay several nights praying that Asclepios would appear in a dream and provide a cure to their ailment.
According to the website of the National Tourism Administration, in 2017, the domestic tourism market has grown at a rapid rate, and the inbound and outbound markets have been steadily developing, and structural reforms on the supply side have achieved remarkable results. The number of domestic tourists reached 5.001 billion, an increase of $12.8 \%$ over the same period of the previous year; the total number of inbound and outbound travel was 270 million, an increase of $3.7 \%$ year-on-year; total tourism revenue for the year was 5.40 trillion yuan, an increase of $15.1 \%$. According to preliminary estimates, the comprehensive contribution of tourism to GDP for the entire year was 9.13 trillion yuan, accounting for $11.04 \%$ of the total GDP. 28.25 million people are directly employed by tourism, and 79.9 million people are directly or indirectly employed in tourism, accounting for $10.28 \%$ of the total employment population in the country.

Therefore, we can clearly see that China will become a major tourist country and the largest outbound travel market. Through the development of the new model of medical tourism, it can enrich the resource model of the domestic market, reduce the gap between rich and poor, and can bring certain economic growth points to the corresponding real economy. It can make a great contribution to precision poverty reduction.

With the development of China's economy, people's demand for medical tourism is also increasing. Chinese tourists travel to South Korea, Japan, the United States, and other countries each year to receive more than US\$5 billion in total consumption of medical services such as beauty, anti-aging, sub-health, and physical examinations. Medical tourism is a new form of integration of medical services and tourism. The development of medical tourism is of great significance in expanding domestic demand, stabilizing growth, promoting employment, benefiting people's livelihood, ensuring health, and enhancing China's international competitiveness. 


\section{LITERATURE REVIEW}

From 2006 to 2015, the development of medical tourism was unstable and showed a rising trend. Between 2007 and 2009, the number of documents was relatively small. After 2009, it developed rapidly, but remained relatively small. Therefore, research on medical tourism in foreign countries is still in its infancy, and the research results are not abundant, and it is urgent for more scholars to enrich and perfect it.

Global medical tourism is moving toward industrialization. For example, India established the National Medical Tourism Commission and the Medical Tourism Association to formulate a set of laws, policies, strategies and plans for the promotion of health tourism. Medical tourism can attract more than 160,000 foreign tourists to India every year. In Thailand, medical tourism has become a major feature. Every year, more than 2 million foreign tourists travel to Thailand to receive various medical services such as heart, cosmetic surgery and dental surgery, as well as local attractions and customs.

Japan has set up the International Society of Sightseeing Medical Research. It is responsible for coordinating and guiding all universities and medical institutions and tourist facilities located in tourist destinations in Japan to integrate sightseeing tourism with medical services, which to provide foreign tourists with a full set of "tourist + medical" services. As a medical powerhouse in the world, Korea is dedicated to medical teeth, plastic surgery, physical examination, and traditional Korean medicine, and provides a series of favorable conditions related to health and medical tourism.

In recent years, the rapid development of medical tourism has transformed from unilateral tourists from developing countries seeking medical treatment from developed countries to bilateral medical tourism tourists. Traditionally, the health care travel model is usually for patients in developing countries to seek medical services in high-end medical centers in developed countries. With the improvement of medical standards in developing countries, low-cost medical expenses, transportation and travel expenses, faster medical services, and the development of the Internet have attracted more and more developed-country patients to come to developing countries for medical treatment. At present, the flow of international health and medical tourism industry is mainly the medical tourism patients in developed countries such as the United States, Canada, and Western Europe to India, Thailand, Malaysia, Singapore and other Asian countries.

\section{SWOT ANALYSIS}

\section{A. Disadvantages}

There are also some problems in the development of medical tourism. The main manifestations are as follows:

Firstly, the reimbursement of social security in China's offsite medical services has not yet been facilitated. For off-site tourists, they can only personally bear all the costs of health care.

The second is the lack of professionals in medical tourism specialization, and the integration of medical and tourism industries demands higher requirements for talents. Talents are required to have a good professional basis in both tourism and medical care, but there is a shortage of talents in this area.

Third, the quality of medical tourism products is uneven, and there is a lack of unified construction planning and guidelines. Fourthly, there is a lack of propaganda and methods for medical tourism products. Many medical tourism products are still unknown.

\section{B. Advantage}

- Drive the development of the industry. Peripheral industries such as medical tourism intermediary service agencies, pharmaceutical and pharmaceutical companies, medical device manufacturing companies, hospital organizations, transportation service agencies, hotels and hotels, convention and exhibition services, souvenir manufacturing companies, tourist attraction operating units, translation organizations, and buildings, etc. The development of the medical tourism industry and common development have a common influence. Not only medical tourism has driven the development of other industries, but other industries have also contributed to the medical tourism industry. According to the World Tourism Organization, a one-dollar income from tourism can boost the income of other industries by four dollars, and the medical tourism industry is more economically motivated. Therefore, the development of tourism is the key to regional economic development and the driving force for the development of various industries.

- Drive urbanization development. Urbanization refers to the population shift from rural to urban areas, "the gradual increase in the proportion of people living in urban areas", and the ways in which each society adapts to the change. It is predominantly the process by which towns and cities are formed and become larger as more people begin living and working in central areas. The United Nations projected that half of the world's population would live in urban areas at the end of 2008. It is predicted that by 2050 about $64 \%$ of the developing world and $86 \%$ of the developed world will be urbanized. That is equivalent to approximately 3 billion urbanites by 2050, much of which will occur in Africa and Asia. Notably, the United Nations has also recently projected that nearly all global population growth from 2017 to 2030 will be absorbed by cities, about 1.1 billion new urbanites over the next 13 years. 
The vigorous development of medical tourism will directly bring about changes in the operational structure of land finance, industrial transformation, real estate, etc., with the development of urbanization, and will provide them with higher economic benefits. Therefore, the key to developing a brand-new economic model when medical tourism and urbanization can be combined organically can not only break through the traditional tourism industry's thinking restrictions, but also break the economic income model in which the tourism economy has been declining year by year.

\section{SOCIAL BENEFITS}

- Improve the popularity. At the current stage, many countries have gradually started medical tourism. Through this method, it has gradually established its good reputation and brand effect. It has a certain reputation and reputation both for the country and for the development of the city. For example, in the Wudalianchi Scenic Area of China, it combines the health care effects of tourism, so that people can enjoy the beauty of tourism while enjoying the corresponding health care effects. It is precisely because of this that the Wudalianchi Scenic Area have been generally welcomed by people, allowing people to linger and forget about it, which has further enhanced their popularity in the market.

- Facilitate the development of tourism. Combining medical treatment with tourism is fundamentally a driving and development of the tourism industry. The ultimate goal is to increase the economic income of the region or country. Medical tourism is the integration of tourism resources and other resources on the basis of tourism, allowing medical services to subtly penetrate into all aspects of people's tourism life. For example, Singapore has gradually implemented the physical examination industry on the basis of the original tourism industry. This allows people to be more clear about their physical condition in the process of tourism, so that the tourism industry and the medical industry can be presented in front of people in a new mode.

- Promote the medical service industry. The development of medical tourism will drive the advancement of medicines, medical equipment and other industries, and promote the increase of related products. For example, in Dubai, the total trade volume of its medical equipment and medical supplies has reached US\$1 billion. As a result, this is a great boost to the health care industry in a region or country, and it can also increase the popularity of local medical services to a certain extent, so that medical services in regions or countries are attracting more and more attention. And attention.

\section{STRATEGIES}

The development of medical tourism can not only promote health services and tourism, but also drive the development of other related industries, such as catering, accommodation, transportation, exhibitions, entertainment, shopping, medical device manufacturing, pharmaceutical manufacturing, construction, etc., which can effectively pull the macro Economic Growth. In addition, the development of international medical tourism is also conducive to further exerting the cost advantage of China's service industry and leveraging the opportunity of a new round of industrial restructuring across the world to promote the development of domestic high-end service industries and improve China's participation in the international industrial chain status.

- Improve relevant laws and regulations. In recent years, China has also vigorously promoted the promotion of medical tourism, but it has not yet formed a single law. As a special tourism project, medical tourism must have laws and regulations for management and guidance so that it can avoid setbacks and difficulties in the development process. In comparison with some foreign countries where tourism is also dominant, the relevant laws and regulations for medical tourism are quite inadequate, and countries such as India, the United States, and Japan are stepping up their legislative work.

- Therefore, in the case of Jinan City, Shandong Province, it should be improving the legal gap in related fields through the formulation of relevant rules and regulations. At the same time, we must also pay attention to drawing on the advanced concepts and experiences of other countries or identities, and combining with the actual conditions of our province and our city, formulate a series of programs to promote the economic development of medical tourism in China. In the process of establishing regulations, rules and regulations, we must focus on the consumer as the center, and we must pay particular attention to ensuring the legitimate rights and interests of elderly consumers and comprehensively consider economic development.

- Improve the quality of tourism professionals. China's medical tourism industry started relatively late. There is no system and department that specializes in cultivating related talents. Whether it is an intermediary or a medical organization, foreigners have already possessed higher professional qualities and capabilities. Therefore, Jinan City, Shandong Province should strengthen the quality of professionals.

- First of all, it is necessary to carry out relevant training in conjunction with advanced medical equipment, conduct training on advanced medical devices, and provide appropriate training on methods of medical services targeted at the elderly. Secondly, Professionals must pay attention to the mastery of multiple languages in the process of carrying out medical tourism.

- Seek highlight features. The dominant project of China is mainly in traditional Chinese medicine. Therefore, 
the development of these advantageous projects can increase the influence and popularity of medical tourism in China. These contents are also more liked by older friends. At the same time, projects such as acupuncture and moxibustion, cupping, scraping, medicinal meals, hot springs, and Tai Chi in China also have their own characteristics, demonstrating the profoundness of China's medical tourism projects. The cities that develop medical tourism can carry out reasonable tourism activities based on the characteristics of Jinan City and different regional cultures, so that the advantages of our city can be demonstrated to the greatest degree.

- Integrate medical and tourism. China's world cultural heritage is relatively large, and its natural scenery and ethnic culture are quite rich. Integrity of medical and tourism can attract more tourists. For example, Baotu Spring in Jinan City, Shandong Province has long been known internationally and has been loved by many tourists. Especially for the elderly, traveling in Baotu Spring has a certain medical effect. Therefore, in the process of carrying out medical tourism in Jinan City, Shandong Province, we must pay attention to the real integration of medical treatment and tourism, so that medical treatment can be integrated into tourism, so that tourism can provide better medical services for the elderly in the process of development. So that the combination of the two values, let people feel the practicality of medical tourism and spiritual cultivation. Through the personal feelings of elderly tourists, the combination of medical treatment and tourism has become closer, and more and more elderly people have enjoyed the medical services and spirit during the tourism process.

\section{CONCLUSION}

In order to better follow up with the elderly and provide better services for the elderly, Jinan City, Shandong Province, must pay attention to innovation and research in the process of tourism development, and pay attention to the new promotion through the development of the medical tourism market. The purpose of economic development and promoting social harmony and progress is to truly enable older people to obtain better travel and living conditions and to create a better medical tourism market in the context of aging.

China's tourism resources are very rich, especially in the field of traditional Chinese medicine has traditional technology and a vast market, China has a unique advantage in the development of medical tourism. With the continuous support of policies, China's medical tourism is bound to usher in a new period of rapid development.

\section{ACKNOWLEDGMENT}

Author: Lin Qian (1979 - ), female, master postgraduate, mainly studied the direction of tourism and hotel management.

Source of the project: This dissertation is a phased study of the Shandong Provincial Institute of Humanities and Social Sciences Research Project, which is the "Research on the Development of Medical Tourism Market in Shandong Province under the Background of Aging" (Project Number: J15WB77).

\section{REFERENCES}

[1] Pafford B. The third wave-medical tourism in the 21 st century [J] Southern Medical Journal, 2009, 102(8):810-13.

[2] Macready N. Developing countries court medical tourists [J]. The Lancet, 2007, 369(9576):1849-1850.

[3] Connell J. Medical tourism: Sea, sun, sand and surgery [J]. Tourism management, 2006, 27 (6):1093-1100.

[4] Connell J. Contemporary medical tourism: Conceptualization culture and commodification [J]. Tourism Management, 2013, 34:1-3.

[5] Heung V C, Kucukusta D, Song H. A conceptual model of medica tourism: Implications for future research [J]. Journal of Travel \& Tourism Marketing, 2010, 27(3):236-51

[6] Smith P C, Forgione D A. Global outsourcing of health-care: a medical tourism decision model [J]. Journal of Information Technology Case and Application Research [J]. 2007, 9 (3):19-30.

[7] Peters C R, Sauer K M. A Survey of Medical Tourism Service Providers [J]. Journal of Marketing Development \& Competitiveness [J]. 2011, 5 (3):117-126.

[8] Gan L L, Frederick J R. Medical tourism facilitators: Patterns of service differentiation [J]. Journal of Vacation Marketing, 2011, 17 (3):165-183.

[9] Sarantopoulos I, Vicky K, Geitona M. A Supply Side Investigation of Medical Tourism and ICT Use in Greece [J]. Procedia Social and Behavioral Sciences, 2014, 148:370-377. 